jados, desenganados, não formaremos amanhan ao lado dos que crêem no "nihil sub sole novum" do preceito biblico?

Mas por emquanto porque não sonhar? Talvez o unico pedaço aproveitavel da existencia seja aquelle que passamos no mundo luminoso e transcendental dos proprios sonhos".

\title{
Oração de paranympho
}

\section{Dr. Francisco Morato}

\begin{abstract}
Discurso proferido pelo Professor Doutor Francisco Morato, paranympho da turma de bachareis de 1935, nas commemorações da formatura dos mesmos, realizada em 18 de abril de 1936.
\end{abstract}

"Levantando minha voz neste bello sodalicio de confraternisação academica, é cheio de alegria e desvanecimento que vos agradeço, a vós outros, bacharelandos de 1935 e bachareis de 1936, meus discipulos de hontem, collegas de hoje e seguramente mestres de amanhan, a generosidade com que me elegestes para vosso paranympho.

Commove-me a fineza de vosso gesto e predilecção.

$\mathrm{Na}$ honrosa investidura com que me engalanaes, tão conspicua na espontaneidade com que desce de vossa indulgencia quão agradecida nas palpitações que gera em meu coração, hei-de sempre reconhecer-lhe o sentido com que a conferis e a intelligencia com que me cumpre recebel-a. E' a tunica de nuncio de vossos sonhos e esperanças, de precursor de vossos dotes e talentos, de arauto das palmas com que vos laurearam as pugnas escolasticas, de mensageiro dos bons augurios que vos ensombram no portico da vida pratica, de assistente sempre presente em espirito em todos os lances e aventuras da carreira profissional, de um como protagonista nos jubilos e expansões que vos inundam 
a alma, de um verdadeiro "pater in divinis", consoante se lhe chama na linguagem sempre expressiva da liturgia.

Commovem-me as palavras de vosso eloquente orador, attribuindo-me predicados e virtudes que a consciencia de minha pouquidade só logra descobrir na cegueira de vossa estima e benevolencia.

Vejo dellas, como já antes havia visto da communicação collectiva que me tinheis levado da eleição, que triplice foi a vossa gentileza. Gentileza da escolha, destacado como fui dentre insignes cathedraticos, sem embargo de não ter tido a honra de collaborar na turma docente que vos acompanhou até o ultimo estadio do ensino escolar; gentileza do modo da escolha, vencedor como quizestes que eu fosse, sem opposição no seio de vosso collegio eleitoral; gentileza da razão da escolha, estribada como fôra no motivo da amizade e justiça, brandura e respeito, disciplina e solidariedade que tenho procurado seguir na regencia e direcção da gloriosa e tradicional Faculdade de Direito de São Paulo, com os applausos dos meus superiores, dos meus collegas, dos meus auxiliares e da sempre generosa mocidade academica.

Animado de vosso apoio e abroquelado nas dobras da dignidade em que me investistes, posso, quero e devo compartilhar do jubilo e festividades com que vos despedis dos sonhos e doçuras de estudantes.

Ha-de vos sacudir a memoria e despertar saudade, em todos os tempos e circumstancias, a lembrança da cerimonia em que hoje vos congregaes, como na cumiada superna de uma serrania a contemplar o passado e o futuro, aquillo que foi e aquillo que ha-de ser. Ha-de se vos gravar no animo, eterna como o proprio espirito, a dupla significação da festividade que hoje celebraes.

Por um lado, é o termino da vida academica, que perlustrastes despreoccupados e porventura algo despercebidos dos labores, maldades, detrimentos e desenganos que formam a trama da peregrinação do homem pela terra. E' a des- 
pedida da Escola, onde a convivencia, á semelhança da passagem pelas casernas e pelos claustros, cria amizades perpetuas, refreia o egoismo, desenvolve o devotamento ao proximo, purifica os costumes, estimula o amor á patria, suffoca o gosto das frivolidades e excita, acima de tudo, o sentimento collectivo, que é factor de progresso social e individual. E' o abandono do remanso onde ensaiastes os primeiros surtos e onde se bosquejaram os contornos de vossa formação intellectual, tão irreductiveis e perennes como as primeiras impressões que se debuxam nas cellulas ainda virgens da natureza juvenil.

Por outro, é o momento da dispersão, a partida para novos rumos, o vestibulo da vida pratica, onde as lutas dos negocios e os vaivens occasionados da existencia avivam lembranças de tempos que se repetem immutaveis para os que surgem de novo, mas que são idos e definitivamente findos para os que por elles uma vez transitaram. Dia de festas e de jubilo, pelo assignalar simultaneamente, em faces oppostas, o termo de uma etapa vencida e o introito de etapa por vencer, os transportes de um estadio que finda e as esperanças de um estadio que começa.

Si tendes a alma abrazada de contentamento e enthusiasmo pela caminhada que concluistes, voltae o coração e a intelligencia para a jornada que iniciaes.

Rasga-se diante de vós novo e vastissimo scenario, para o qual volveis como quem de relance descortina longinquos horizontes, o olhar fito no circulo vago e nebuloso onde o céu e a terra se tocam, despercebidos dos resaltos e rebaixos que se succedem no panorama inferior á linha visual, crente de que só o azul, o purpura, o rosa e o branco matizam a tela variegada da vida humana.

Cedo havereis de experimentar quão variados e irremoviveis os accidentes que povoam a estrada por onde parmilhamos, quão cheias de repentes e inesperados as lutas em que nos empenhamos, quão incertos, penosos e occasionados os triumphos que logramos alcançar. Com cedo tereis de ver que de um geito ou de outro, assim ou assim, 
uns mais poupados outros mais provados, haveremos todos de contribuir com o nosso escóte á precariedade e contingencia, que são o mais notavel apanagio da natureza finita da criatura.

Não vos atormente, porém, nem vos alarme o contraste entre o sonho e a realidade, entre os prazeres do passado e os perigos do futuro, entre o goso de uma empresa terminada e as afflicções de uma tarefa a afrontar.

A vida é sempre assim; mal acabada uma obra, outra para logo cumpre começar. Quando o homem tiver acabado, estará então no começo, dizem as escripturas - "cum consummaverit homo, tunc incipiet".

Nunca vos seria licito pretender finda uma missão que apenas preparastes; a tarefa está verdadeiramente no começo - "tunc incipiet".

Mas não ha motivo para inquietações, senão para que vos considereis confiantes no bom successo final, sob a armadura bemfazeja, que é o preparo e os galões com que vos adornou e vos lança ao mundo a querida Academia de Direito de S. Paulo; o exito do que começa é assegurado pelo exito do que acaba.

A data da formatura, como todas as datas culminantes da vida, é um despertar de esperanças.

Soam as vozes de despedidas e os toques de separação; mas que estes e aquellas vibrem e tanjam á maneira dos canticos de fé que os crentes elevam para as alturas, fundidos e misturados em caminho para o céu.

Começa para vós a dispersão; mas que a dispersão vos separe os corpos, as vocações, o destino, não as vozes nem os corações - nem as vozes, nem os corações, nem a fé, nem a fortuna, nem o orgulho das letras que versastes.

Trazeis as insignias de um secular e prestigioso seminario de jurisprudencia; sois juristas e o officio do jurista, conforme temos pregado da cathedra e da tribuna das conferencias, é dos mais nobres, intrincados e dignificantes na nomenclatura e hierarchia das profissões liberaes, tanto pelos predicados que exige de aptidões literarias, acuidade de in- 
telligencia, dotes de espirito, variedade de conhecimentos, visão omnimoda das coisas da vida, quanto pela funcção synthetica e capital de distinguir na theoria e na pratica o justo do injusto, de assegurar no sentimento da justiça o equilibrio de todas as forças moraes do universo, de realisar o Direito, aquillo que é a mais impreterivel condição da existencia organisada, a propria medula da vida collectiva e individual, o fundo e substancia de todas as relações no trato dos homens, das familias, das sociedades e das nações.

Das difficuldades e relevancia da profissão resulta a estima e primado dos profissionaes.

Em que pese aos que, tocados de inveja, rivalidade ou inconsciencia murmuram contra o que pejorativamente denominam a casta dos bachareis, certo é que aquelles que com preparo, vocação e treino se dedicam ao mistér de defender o organismo juridico social, adquirem uma pericia e superioridade que refojem ao commum dos homens, na elaboração e intelligencia das leis, no trafico da vida civil, no entravamento e meneio dos negocios publicos.

Não ha vituperal-os de se arrogarem vaidosamente preeminencia entre os que exercitam na vasta e luminosa esphera da intellectualidade. Sua profissão não é privilegio de ninguem; está aberta a quem queira disputal-a.

Não é o jurista que retira da scena o homem do mundo; o jurista entra em scena, precisamente porque o homem do mundo tem necessidade delle.

Não ha increpal-o de monopolio de uma competencia estranha ao geral dos homens. Isso está na natureza das coisas. Quem tiver inveja ao jurista, faça-se jurista e depois vista-lhe a toga e professe-lhe as excelsas prerogativas.

Attentai bem, meus caros amigos, na grandeza da missão social dos sacerdotes de Themis e na correspondente somma de virtudes e prendas que reclama.

Ao jurista digno de suas letras e dos bordados com que exercita, cumpre-lhe ser psychologo para conhecer os pre- 
dicamentos, vicios e fraquezas de seus semelhantes; ser generoso, afim de pairar acima dos attractivos dos prazeres e da cupidez; ser dotado de grande intelligencia, de grande discernimento e de grande segurança, para não claudicar na applicação das regras e principios; ser abnegado, para não esmorecer no zelo e patrocinio da innocencia; ser intemerato, para jamais faltar aos deveres da honra e probidade; ser intrepido, para nunca falar senão a linguagem da verdade.

Cumpre-lhe, á imagem e semelhança do soldado no campo de Marte, ser cioso da autoridade das leis, da nobresa de sua missão social e da força dos instrumentos com que collabora na harmonia geral.

Cumpre-lhe o dever ademais de enthesourar dia a dia solidos conhecimentos scientificos e não esquecer as riquezas, ornatos, elegancias e finuras em que são cabaes os familiares com as bellas letras e bellas artes.

Corre-lhe o dever de não descurar estas observancias, guardada a sobriedade sempre de rigor na palavra escripta ou falada do homem da lei. O estylo do jurista é o da synthese, da singeleza e da claridade; tão conciso, tão simples e tão diaphano como a propria idéa de justiça.

Nem outro deve ser o methodo e caminho nas artes plasticas e nas digressões literarias. Mesmo ahi, nas mais perfeitas e buriladas das composições, a prolixidade fatiga o ouvinte ou leitor, obliterando-lhe a sensibilidade esthetica e empanando-lhe o brilho da oração.

Ruy Barbosa reconhecia que suas conferencias eram de ordinario largas e derramadas, ostentando no torvelinho de uma verbalisação opulentissima e de periodos luminosos, um cultor eximio da amplificação e da paraphrase, superior a Victor Hugo. Assim reconhecendo, notava todavia que não seria diffusa a mais copiosa das orações, quando o assumpto não comportasse menos dilatado tratamento; não haverá prolixidade em não havendo sobejidão.

Nestas apreciações de tamanho, escrevia o insuperavel polygrapho na sua conferencia "A imprensa e o dever de 
verdade", não se percam de vista as noções de relatividade e proporção. A "Illiada" consta de vinte e quatro rhapsodias, e de vinte e quatro a "Odysséa". Já o grande poema de Vergilio, a "Eneida", não se compõe senão de doze livros; nem mais de outros tantos deu Milton ao seu "Paraizo Perdido". Com "Os Lusiadas" ainda baixa a conta: são apenas. dez cantos. Mas os da "Divina Comedia" montam a cem. E quem, porisso, irrogaria ao Dante a nota de perluxo? O florentino responderia com vantagem que, onde couberam os heroes de Homero, Vergilio, Milton e Camões, não caberia o inferno, o purgatorio e o paraiso, Deus, o tempo e a eternidade.

Mas a longura é sempre longura, ainda mesmo na penna ou no verbo lampejante e impeccavel da aguia da latinidade e do genio brasileiro.

Não ha materia por mais vasta que seja que não comporte tratamento breve, resumido e substancial. O Genesis descreve em poucas linhas a maior maravilha que registam os fastos divinos e humanos - a historia da criação do mundo.

Lafayette vasava seus trabalhos juridicos e resolvia intrincadas questões em forma invariavelmente breve $\mathrm{e}$ elegantissima; em estylo que pela clareza, concisão, propriedade de termos, harmonia e vigor pede meças ao phrasear de Papiniano, Mackeldy, Blackstone, Mourlon ou Planiol. Não era porém apenas na jurisprudencia que se revelava o estylista, senão tambem nos dominios das letras. em geral.

Haja vista seu bello livro "Vindiciae", monumento de bom gosto e de critica. Haja vista o Prologo que escreveu á traducção do "Prometheu Acorrentado".

D. Pedro II havia vertido do grego para o vernaculo a famosa tragedia de Eschylo. Feita a versão, pediu a $\mathrm{Pa}$ ranapiacaba lh'a puzesse em versos e que, em seguida, submettesse traducção e versos á emenda de Lafayette, autoridade para quem não havia segredos no hellenismo, na metrificação e na literatura. 
Lafayette correu os olhos e a lima sobre o trabalho de um e de outro, e depois, por solicitações do poeta, escreveulhe um prefacio, que encanta pela perfeição, simplicidade e espirito com que define a tragedia grega e resume o poema de Eschylo, a seu ver um dos productos mais assombrosos do genio antigo e um escrinio de sublimidade, primores e excellencias, que têm arrancado gritos de admiração aos criticos de todas as edades.

Lembrando insistentemente aos discipulos as qualidades fundamentaes do discurso, já postas em relevo nos "Tratados de Eloquencia" e no proloquio latino "pauca sed bona", costumava Julio Ribeiro fazer curiosa e faceta classificação. Pode o discurso ser de quatro categorias, dizia o preclaro philologo mineiro: mau-bom, bom-mau, maumau, e bom-bom. Mau-bom, o comprido e bem feito; bommau, o curto e mal feito; mau-mau, o comprido e mal feito; bom-bom, o curto e bem feito.

A synthese é que é difficil; a synthese é que é a expressão do bello e sublime nos torneios da intelligencia e das artes.

Não ha orador por mais facundo e academico que seja, que consiga prender o auditorio depois de uma hora de attenção. Não ha escriptor, por mais lapidares e atticas que lhe saiam as phrases, que logre encantar, quando ziguezagueia em palavras e torneios indefinidos ao redor do mesmo assumpto ou pensamento. Não ha musicista por mais que se preze de opulento, original e cathedratico, que alcance a fortuna de commover a platéa, quando perde a medida e compasso do tempo.

Tome-se, por exemplo, uma das monumentaes partituras de Wagner, os "Mestres Cantores", o "Parsifal" ou outra semelhante. Tudo ahi é assombroso - as fugas de violino, as novidades de metal, o jogo das massas vocaes, a repetição insistente dos motivos em todos os naipes da orchestra, a eliminação da melodia, a imponencia do conjunto, a majestade da harmonia, a transformação da opera em drama musical, a sujeição da musica á realidade do texto, a maes- 
tria e paciencia suprema do compositor; tudo é assombroso, mas acaba adormecendo os espectadores e os proprios sabios dilettantes que monopolisam a prerogativa de serem os unicos em estado de comprehender com Morpheu os encantamentos da obra wagneriana.

O espirito, por uma lei de biologia mental, não supporta as demasias, nem mesmo as dos primores e bellezas, pela razão que o homem não aprecia senão o que comprehende e a comprehensão é incompativel com o cançaço. A prolixidade gera o cançaço e o cançaço tolda o conhecimento e estiola a faculdade sensitiva. O bello não depende somente de sensibilidade, senão tambem de intelligencia.

Mas, perdoae-me meus jovens collegas, esta divagação e relevae-me se incorro com ella o peccado que venho condemnando.

Ides dispersar-vos. Parti; parti com os votos dos collegas que deixaes no grupo dos antigos mestres. Se alguma coisa ainda podemos accrescentar na despedida, queremos aconselhar-vos que marcheis mansos, alegres e unidos; queremos imitar José, quando desejando assegurar aos irmãos feliz retorno á casa paterna, só lhes deu de conselho que não se encolerisassem em caminho.

A mansidão produz a alegria; a alegria encanta a vida; a vida encantada é a victoria.

Marchae alegres e contentes, intrepidos e resolutos.

Quando futuramente, nas lutas esplendorosas da jurisprudencia, nas pugnas enganadoras da politica, nos ardores das refregas literarias, nas riquezas das expansões industriaes, na abundancia do commercio prosperante, nas conquistas applaudidas das bellas artes, na serenidade bucolica da vida campezina ou nas doçuras ineffaveis do lar, perceberdes attingida a meta de vossas aspirações e ouvirdes vozes laudaticias de victoria, lembrae-vos que esse triumpho será uma projecção das glorias da Faculdade de Direito de São Paulo e que no côro dessas vozes estão sempre, sempre presentes, os votos de vosso paranympho.

Lembrae-vos de tudo isso e não vos esqueçaes dos "bonbons" de Julio Ribeiro". 